\title{
CINE E HISTORIA EN LA ARGENTINA: UN ESTADO DE LA CUESTIÓN
}

\author{
FILM AND HISTORY IN ARGENTINA: A STATE \\ OF THE ART
}

\author{
Mariana Piccinelli* \\ Florencia Dadamo** \\ Leandro Della Mora***
}

\begin{abstract}
Resumen: Las películas son representaciones culturales de sociedades que son sus productoras y a la vez sus consumidoras. Vivimos en una época posliteraria en la cual el acercamiento masivo del público hacia el conocimiento del pasado se lleva a cabo desde el cine. Es por esta razón que los historiadores no podemos dejar de lado una herramienta tan importante como lo es este medio audiovisual y darnos el lujo de ignorar las producciones cinematográficas que participan activamente en la construcción de la memoria histórica. Resulta necesario entonces dar cuenta de las características y potencialidades propias de la imagen sin por ello dejar de lado el objetivo de realizar un análisis discursivo de los textos fílmicos desde un punto de vista histórico. Diversos autores y colectivos académicos de la Argentina en los últimos años han reparado en estas cuestiones. En este artículo presentaremos un estado de la cuestión sobre la relación cine-historia teniendo en cuenta producciones académicas argentinas que estudian el abordaje fílmico del pasado desde la Historia como disciplina. A los efectos de este objetivo se relevarán diversos artículos, publicaciones y ponencias realizadas durante los últimos tiempos.
\end{abstract}

Palabras Claves: Cine. Historia. Estado de la cuestión. Argentina.

\footnotetext{
* Licenciada en Historia, Fac. Filosofía y Letras, Universidad Buenos Aires (UBA) y Doctoranda UBA. E-mail: marianapiccinelli@hotmail.com

** Licenciada en Historia, Fac. Filosofía y Letras, UBA. E-mail: dadi_mfd@hotmail.com

*** Licenciado en Historia, Fac. Filosofía y Letras, UBA.

E-mail: leandrodellamora@hotmail.com
} 


\begin{abstract}
Films are cultural representations of societies that are both their producers and consumers. We live in a posliterary era, where the general public approaches to their past come from the cinema. That's why historians cannot leave aside such an important instrument and ignore cinematographic productions that contribute to build the historic memory. Therefore, we need to consider the properties and possible uses of the image and, at the same time; we should analyze the filmic discourse from an historical point of view. Many research teams and authors in Argentina have notice these matters during the past years. In this article we will present a state of the art in the history-cinema relationship, including academic researches about filmic analysis of the past from the history as a science. To achieve these goals we will considerate several articles, publications and papers written over the last years.
\end{abstract}

Keywords: Cinema. History. State of art. Argentina.

\title{
INTRODUCCIÓN
}

El cine como institución de la sociedad contemporánea siempre generó una fascinación particular entre los investigadores, en tanto arte y discurso. Como historiadores no podemos negar que este medio ha ganado un lugar en el terreno de nuestra disciplina. Hoy en día es común la utilización de las producciones audiovisuales en la enseñanza de la materia en todos los niveles escolares. En muchos casos las películas son la vía de acercamiento más rápido y eficaz de las personas al relato de su propio pasado.

Por ello, la consideración de un film desde la ciencia histórica es un proceso complejo y no exento de controversias. ¿Qué sucede cuándo la Historia supera el terreno regular de la escritura para adentrarse en un área que posee sus propias reglas, muy distintas a los condicionamientos e implicancias de la palabra escrita?

Según Fabio Nigra “...existe un punto de tensión teórico que resulta verdaderamente complejo de resolver, y es si las películas pueden ser escritura de la historia o son simplemente fuentes históricas del momento en que fueron filmadas". ${ }^{1}$ Este es básicamente el eje del debate conocido como FerroRosenstone $^{2}$, que si bien data de tres décadas, hoy sigue marcando el ritmo de las publicaciones dedicadas a la relación entre el cine y la historia.

En la Argentina el abordaje de esta problemática comenzó tímidamente a fines del siglo XX y poco a poco fue ganando terreno en las discusiones académicas. El objetivo de éste trabajo es presentar un estado de la cuestión sobre los estudios que analizan la relación entre el cine y la historia llevados a cabo en nuestro país en los últimos años. En especial intentaremos dilucidar 
qué nivel de desarrollo ha alcanzado este debate y cuáles son las herramientas teórico-metodológicas que priman en la bibliografía actual.

En este proceso, nos centraremos en aquellas producciones académicas que tengan como objeto de estudio el cine ficcional ${ }^{3}$ desde la ciencia histórica. Debido al carácter polifacético del film, encontramos algunas excepciones a nuestro encuadre. En muchos casos hay autores que no hacen distinción entre el cine documental y el de ficción. Por otro lado, existen algunos trabajos que analizan la relación cine-historia desde otras disciplinas sociales, por lo cual ciertas aproximaciones interdisciplinarias serán aquí consideradas.

A lo largo de nuestra tarea consultamos un amplio compendio bibliográfico que incluye publicaciones (libros y artículos de revistas), ponencias presentadas en Jornadas y Congresos de Historia ${ }^{4}$, proyectos de investigación grupales e individuales, programas de seminarios y cursos y notas de divulgación académica.

El interés en dichas cuestiones deriva de nuestra propia labor como historiadores enmarcados en un proyecto de investigación de la Universidad de Buenos Aires. El mismo se centra en la idea de que ciertas películas no sólo reproducen una narración histórica, sino que también proporcionan una interpretación del hecho al que se refieren y lo hacen a través de un lenguaje particular. Si bien no es equiparable a la historiografía, esta interpretación no puede ser obviada por la Academia, ya que en muchos casos alcanza entidad y valor social e incluso compite con las versiones eruditas del pasado.

El presente artículo está estructurado sobre tres ejes: el primero da cuenta de los grupos consolidados de trabajo que incursionan en la temática que nos atañe. Estos están constituidos por aquellos colectivos académicos o profesionales que plasmaron sus avances en producciones bibliográficas y se dedicaron a la formación de recursos humanos, dictando cursos y/o seminarios, manteniendo una labor activa y sostenida a lo largo del tiempo en la propagación de sus investigaciones. El segundo abarca las producciones que por su temática o metodología pueden englobarse dentro de problemáticas comunes; por ejemplo memoria e identidad; cine, Estado y propaganda, etc. El tercer eje menciona organizaciones que desde las artes cinematográficas fomentan el desarrollo de estudios sobre cine e historia.

Por último, a modo de conclusión, realizaremos ciertas reflexiones sobre lo aquí elaborado. Esperamos sirvan como interrogantes o disparadores que puedan ser abordados en un futuro. 


\section{GRUPOS DE TRABAJO}

El análisis de la bibliografía demuestra de la existencia de cinco grupos de trabajo que presentan un arraigo institucional y una producción académica creciente y sostenida en el tiempo. Observados en conjunto podemos decir que el motor principal que dispara la reflexión se desprende de la actividad de sus miembros en distintas Cátedras universitarias. Esto le otorga una impronta particular a cada uno de dichos colectivos que se expresa en el compendio fílmico y en las áreas temáticas que investigan.

El grupo liderado por Fabio Nigra, con arraigo institucional en la Facultad de Filosofía y Letras de la Universidad de Buenos Aires, se ha dedicado principalmente a analizar las relaciones entre el cine norteamericano hollywoodense y la historia de Estados Unidos. Han plasmado su trabajo en artículos publicados en revistas impresas y electrónicas ${ }^{5}$; decenas de ponencias presentadas en Jornadas y Congresos, tanto de Historia como de Cine ${ }^{6}$ y producciones bibliográficas. Estas consisten en dos obras grupales: Hollywood, Ideología y consenso en la historia de Estados Unidos y Visiones gratas del pasado. Hollywood y la construcción de la Segunda Guerra Mundial; y una tercera de Fabio Nigra: Hollywood y la historia de Estados Unidos. La fórmula estadounidense para contar su pasado. ${ }^{7}$

Asimismo Nigra dirigió proyectos de investigación $\mathrm{UBACyT}^{8}$ y ha dictado seminarios de grado y de posgrado de la carrera de Historia en la Facultad de Filosofía y Letras de la Universidad de Buenos Aires. ${ }^{9}$

El grupo inicialmente se internalizó en la controversia RosenstoneFerro, entendiendo a los films norteamericanos como recursos narrativos comparables con los historiográficos, y al mismo tiempo como fuentes de su época de elaboración. Dentro de esta concepción las películas, principalmente aquellas realizadas en Hollywood, son productoras y reproductoras de consenso e ideología, que en la lógica norteamericana se traduce en fomentar la fe en el funcionamiento del sistema estadounidense y los 'valores universales' del American way of life. Creencias y preceptos que se exportan por medio de un imperialismo cultural cuyo aparato ideológico se ha enraizado en las producciones de los grandes estudios norteamericanos que acaparan los mercados de casi todo el mundo. Además de ser embajadores de la idiosincrasia norteamericana, estos films se constituyen como instrumentos de las clases dominantes para la construcción de hegemonía interna.

Las temáticas abordadas atraviesan diversas etapas de la historia norteamericana hasta la actualidad: desde hechos que datan de la fundación y consolidación de la Nación estadounidense, pasando por procesos históricos propios del siglo XX como el desarrollo del movimiento obrero y sindical, la lucha de los afroamericanos por los derechos civiles, la Segunda Guerra 
Mundial, la guerra de Vietnam, la Guerra Fría hasta la actual ofensiva contra el terrorismo. A su vez, los análisis tienen en cuenta un abanico de elementos propios de la sociedad en cuestión como el concepto de su excepcionalismo, el exacerbado patriotismo, el planteo maniqueo entre el bien y el mal, la frontera como mecanismo para la construcción de la democracia y el consenso sobre las bondades del sistema norteamericano. Todos estos aspectos fueron desarrollados por Fabio Nigra como "Invariantes Ideológicos" fácilmente rastreables en los films de Hollywood que de alguna manera abordan el pasado. ${ }^{10}$

Algunos de los trabajos resaltan la posible utilización pedagógica de las películas como herramientas para comenzar o complementar el estudio de procesos y acontecimientos verificables. Además, la mayoría de los escritos desarrollan una profunda contextualización histórica tanto de los hechos relatados en las cintas seleccionadas como así también de la época de rodaje de cada una. Últimamente el grupo está desarrollando los aspectos semióticos de la construcción narrativa del discurso fílmico, tomando a autores como Roland Barthes, Marc Angenot, Eliseo Verón, Hayden White, Roger Chartier, Michel De Certeau e Ismail Xavier.

También desde la Universidad de Buenos Aires, los docentes Laura Radetich y Eduardo Jakubowicz ${ }^{11}$, logran condensar en su obra La historia argentina a través del cine. Las 'visiones del pasado' (1933-2003)12 investigaciones previas presentadas en Congresos de Historia. ${ }^{13}$ Haciéndose eco de los debates iniciados por los teóricos de la "escuela contextual del cine"14, examinan la relación cine-historia y se preguntan por la tarea del investigador frente a las representaciones fílmicas del pasado, quien debería tomar una posición hermenéutica ante las mismas.

El objetivo de su trabajo es plantear una periodización basada en el análisis de diversas producciones audiovisuales argentinas (documentales, largometrajes, cortometrajes, films ficcionales, etc.) que recrean de alguna forma el pasado nacional, destacando las rupturas y continuidades, tanto políticas como culturales de cada época y sus etapas.

A grandes rasgos distinguen tres periodos de expansión y tres de regresión en el cine histórico argentino. ${ }^{15}$ A pesar de que cada uno de estos posee características propias -ya sean estéticas o narrativas- los primeros están caracterizados por una gran cantidad de películas que remiten a procesos y hechos del pasado argentino. Al analizar estos momentos los autores dan cuenta de diferentes fenómenos: contexto histórico nacional e internacional favorable, apoyo estatal activo al desarrollo de producciones fílmicas, e intereses culturales y políticos retomados por nuevas temáticas históricas y por la actividad de sectores o actores sociales hasta entonces relegados. Por el contrario, para los periodos regresivos se tienen en cuenta los mismos factores pero desde una arista negativa. El contexto nacional represivo de censura y persecución, el 
marco internacional de crisis globales o la injerencia de la industria fílmica norteamericana en el mercado interno, influyeron sobre la caída cuantitativa y cualitativa del rodaje de películas que refieren al pasado argentino.

A su vez Radetich, desde su especialización sobre formación docente, se dedicó a profundizar las implicancias pedagógicas que tiene el cine con el objetivo de brindar posibles explicaciones a conceptos abstractos. De esta forma además de tomar a los films como agentes de la historia, explora su posible uso pedagógico, demostrando las múltiples funciones o implicancias del medio audiovisual y de su carácter polifacético (cine como narración, como fuente o documento histórico, como agente o como herramienta didáctica).

Marcela López y Alejandra Rodríguez ${ }^{16}$ también han profundizado en este aspecto pedagógico. Desde hace diez años se dedican al estudio de la construcción cinematográfica del pasado nacional argentino. Cuentan con diversas publicaciones en revistas de divulgación y Congresos. ${ }^{17} \mathrm{Su}$ actividad profesional se complementa con el dictado de charlas y $\operatorname{cursos}^{18}$ sobre cine en instituciones de Educación Superior, como la Escuela de Capacitación Docente (CEPA) y el Centro Cultural Rojas (dependiente de la Universidad de Buenos Aires) y la publicación de textos escolares. ${ }^{19}$

En su obra Un país de película. La historia argentina que el cine nos contó $^{20}$ las autoras logran condensar la mayor parte (aunque no toda) de su labor académica de una forma amena y didáctica. Allí, se analizan una serie de films ficcionales y documentales realizados desde hace casi un siglo para identificar y demostrar la influencia del medio audiovisual en la formación del ser nacional argentino.

Un país de película... se ordena en base a diversos núcleos temáticos que, organizados cronológicamente, exhiben hechos y procesos que se constituyen como hitos de la historia argentina. En distintas secciones se analizan films que por su argumento y estructura resultan pertinentes para el estudio de dichos nudos históricos. En cada capítulo se examinan las películas partiendo de una breve descripción de los acontecimientos y fenómenos que caracterizan el tiempo narrativo de estas producciones cinematográficas, para luego abordarlas tanto en forma individual como comparativamente. Al hacerlo, las autoras atienden al contexto de producción de las obras y las intenciones de cada director para explicar la visión que éstas presentan del pasado argentino.

Lo que resulta relevante entonces es discernir la percepción de la historia que las películas plantean en función del momento en el que fueron concebidas. Es así como el cine puede funcionar como un instrumento de propaganda, como vehículo de construcción de una identidad nacional, como documento de una época o como agente del propio devenir histórico y su relato. Prueba de ello es la importancia, divulgación y popularidad que ciertos films adquieren en la 
versión escolar de tiempos pretéritos. El ejemplo más claro de este fenómeno resulta ser el caso de la figura de San Martín.

En coincidencia con lo expresado anteriormente López y Rodríguez plantean que la mayoría de las representaciones cinematográficas del pasado argentino siguen, en líneas generales, el relato oficial planteado por la historiografía mitrista. Esta visión, concibe a la evolución histórica como la sumatoria de logros individuales perpetrados por grandes hombres en favor de una nación preconcebida. De esta manera, las autoras entienden que la forma más común de narrar cinematográficamente la fundación del país es en clave épica. Sin embargo, dan cuenta de ciertas excepciones y variaciones que presentan algunas producciones específicas -ya sea en sus estructuras como en sus argumentos- que contribuyen a que el relato de la historia nacional desde el medio audiovisual sea polifónico y diverso.

Si bien se trata de dos investigadores que provienen de distintas instituciones y se dedican originalmente al tratamiento de problemáticas diferentes, podemos decir que Zulema Marzorati y Tzvi Tal conforman un grupo de trabajo cuyo mayor logro ha sido difundir los estudios sobre cine-historia en la Argentina. Juntos han coordinado mesas temáticas en Jornadas de Historia desde el año 2001 y actualmente presentaron un Dossier publicado en la revista Imagofagia $^{21}$. En él hacen un recuento de la bibliografía internacional que se ha publicado en las últimas décadas, para luego definir el concepto de cine como "portador de memorias". Para los autores, este medio es uno de los campos culturales donde la memoria se edifica teniendo en cuenta los códigos de la comunicación y las limitaciones sociales dentro de las cuales se practica esta particular reconstrucción del pasado. Si las películas tienen un papel relevante en los procesos de conformación de la memoria, también se constituyen como una herramienta esencial contra el olvido.

Tzvi Tal es docente de la Universidad de Tel Aviv y ha publicado artículos sobre cine argentino y latinoamericano en varios países. ${ }^{22} \mathrm{En}$ su conjunto, estos se enfocan en la influencia del contexto de producción en las películas y destacan la importancia del celuloide en el proceso de configuración del imaginario colectivo.

Zulema Marzorati es Doctora en Ciencias Sociales y actualmente estudia las representaciones científicas en documentales argentinos. Paralelamente ha dedicado sus investigaciones sobre cine e historia al análisis de la filmografía europea de la década de 1930 y la norteamericana elaborada durante el período macartista. A partir del dictado de seminarios ${ }^{23}$ y presentación de ponencias en Congresos ${ }^{24}$, indaga las características del medio audiovisual como una institución esencial de la sociedad contemporánea.

Sus escritos son bastante diversos en cuanto a las temáticas que consideran, sin embargo, podemos trazar algunas líneas teóricas en común. 
Haciéndose eco de los postulados de Marc Ferro y Pierre Sorlin la autora plantea que el análisis del cine contribuye a la construcción del saber histórico en tanto la lectura de los films permite aproximarse a la forma en que los individuos y grupos se percibieron en la época en la que estos fueron elaborados. Las películas toman elementos del universo simbólico que las rodea y constituyen y reproducen imaginarios sociales. Por ello, las producciones cinematográficas revelan tensiones y problemáticas del pasado que ayudan a los historiadores a comprender la realidad en la que fueron concebidas.

Además de sus artículos, debemos destacar su amplia labor universitaria. Marzorati se desempeña como profesora en la Cátedra de Historia Económica y Social General de la Facultad de Ciencias Económicas, en la materia Historia Social Moderna y Contemporánea de la Facultad de Ciencias Sociales (ambas de la UBA) y en la Maestría de Cultura y Salud Mental del Instituto Universitario de Salud Mental. Desde allí ha contribuido a la difusión de bibliografía teórica sobre cine e historia, lo cual ha dado lugar a elaboraciones y enfoques interdisciplinarios.

Así, en Jornadas de Historia encontramos trabajos que estudian la forma en que las relaciones laborales son problematizadas desde la pantalla grande. En su ponencia "El despoblamiento rural bonaerense reflejado en el film Nueva Plata: ;Acusa! de M. Zipilivan", Cristina Matheu ${ }^{25}$ analiza el éxodo campesino de la década de 1930 que tuvo lugar en la Provincia de Buenos Aires. Para ella el film es una puerta de entrada para reconstituir una experiencia social conflictiva. Por su parte Rodolfo Batagliese ${ }^{26}$ examina los cambios en las relaciones laborales francesas expresados en dos películas contemporáneas. Siguiendo los lineamientos de Marc Ferro, que plantea la posibilidad de utilizar el cine como fuente de la historia, intenta descubrir qué representaciones sociales y culturales están plasmadas en los films.

Desde otro enfoque y a partir de su labor académica en la Facultad de Ciencias Sociales de la Universidad de Buenos Aires, Irene Marrone ${ }^{27}$ ha trabajado en el análisis de fuentes documentales cinematográficas argentinas, junto a Mercedes Walter Moyano, Mabel Fariña, Ma. Florencia Luchetti y Sebastián Russo, entre otros sociólogos. ${ }^{28} \mathrm{Si}$ bien abarcan diversos núcleos temáticos y temporales, el eje que atraviesa sus estudios es el desarrollo de procesos identitarios en relación con las prácticas culturales de la época analizada. El cine en este caso es considerado como un espacio para mostrar algunos modos de representación del pasado.

Se destaca una prolífera actividad en proyectos de investigación ${ }^{29}$ que han condensado y a la vez potenciado la elaboración y publicación de una gran cantidad de la bibliografía del grupo. El UBACyT "Atrapando la realidad. Disrupción social y boom documental cinematográfico en los años sesenta y noventa en Argentina" tuvo como objetivo examinar las prácticas culturales 
y la conformación de la identidad en dos períodos que los investigadores consideraron claves para la participación de ciertos sectores sociales en la escena pública, como fueron la década de 1960 y la de 1990.

Según Irene Marrone y Mabel Fariña la irrupción de la protesta social trajo la aparición de una gran cantidad de documentales que se hicieron eco del conflicto que aparece en escena. Al respecto observan que a mediados de la década de 1990 hubo un cambio sustancial en la producción cinematográfica. Si en la etapa inmediatamente posterior al retorno de la democracia se prefirió el género de ficción antes que el documental (posiblemente por el temor que reinaba en el ambiente), en "los noventa" surgió una nueva generación de directores que compartieron la preocupación por los problemas sociales como la desocupación, la marginalidad o la delincuencia y recurrieron al género y a la estética documental para plasmar su visión de la realidad. Es así como, gracias al documental, el verismo testimonial se instaló como modo de expresión y como forma de construir la memoria.

Para Sebastian Russo ${ }^{30}$, los documentales subjetivos contemporáneos abordan paradigmáticamente la estructuración identitaria puesto que a partir de un duelo personal que se traduce en narraciones íntimas del pasado, se puede reconfigurar la memoria colectiva. El análisis de la película $\mathrm{M}$. de Nicolás Prividera le permite examinar el proceso de construcción de esta memoria común en la relación entre lo público y lo privado, entendiéndola como un campo de disputa.

En la actualidad el grupo se encuentra trabajando en el UBACyT "Lo político y el documental cinematográfico en Argentina. Hacia una historia integral del documental cinematográfico en Argentina. 1897-2009”. Este posee un carácter más práctico puesto que además de intentar realizar una historia integral del documental cinematográfico argentino, se proponen digitalizar e inventariar todo el material audiovisual donado al Centro de Documentación Audiovisual del Instituto Gino Germani para su puesta en consulta.

Si seguimos la línea rectora que trazamos al comienzo del artículo, que involucra aquellas producciones que desde la historia analizan el cine ficcional, es claro que el colectivo de Irene Marrone no comparte muchos de los conceptos planteados en nuestra introducción. Sin embargo consideramos que debe ser incluido en la presente reseña por varias razones. En primer lugar, es uno de los pocos grupos que presenta un arraigo institucional claro y sostenido a lo largo del tiempo cuya producción es progresiva y sumatoria. Por otro lado, ellos mismos encuadran su labor dentro del campo disciplinar que nos interesa. Según estos investigadores, no existe una diferenciación entre las películas de ficción y las formas documentalizadas del cine. Ambas son construcciones subjetivas y como tales pueden ser analizadas desde una perspectiva histórica para observar e interpretar a la sociedad y sus cambios. 
En general, la mayoría de los trabajos argentinos sobre cine-historia no consideran este tipo de aspectos teóricos en torno a la naturaleza del film (ficción, ficción histórica, documental, docudrama, etc.). En muchos casos se realizan estudios comparativos sin tener en cuenta el carácter diferente de los objetos que están analizando. Creemos que es necesaria una mayor precisión en el uso de los conceptos teóricos a la hora de abordar los films, tanto si se adoptan criterios de análisis provenientes de la bibliografía especializada como si se plantean ideas propias.

Por último debemos señalar que la mayoría de los colectivos reseñados tienen su sede en la Universidad de Buenos Aires, desde donde potencian la investigación y difusión de la bibliografía a otros ámbitos educativos. Si bien existe una gran cantidad de profesionales pertenecientes a otras instituciones nacionales que publicaron trabajos durante la última década, notamos que no tienen continuidad y desarrollo en el tiempo. A su vez, esto genera una disparidad en la producción académica, que se concentra en Buenos Aires. Es por ello que rescatamos aquellas instituciones que promueven proyectos de investigación sobre cine e historia. ${ }^{31}$ Esperamos que en un futuro estos grupos crezcan y se multipliquen. Esto permitiría dar un paso en la articulación de las producciones nacionales y generar debates constructivos que ayuden al crecimiento del campo.

\section{GRUPOS TEMÁTICOS}

A lo largo de nuestra búsqueda encontramos conceptos y cuestiones recurrentes que nos han servido para articular a una serie de autores, a pesar de que éstos no presentan relaciones institucionales entre sí. A continuación expondremos brevemente un conjunto de investigadores que por su labor académica hemos decidido abordarlos desde las temáticas que ellos analizan y distinguirlos en ciertos ejes vinculados a las mismas.

Dentro de los estudios que podríamos llamar regionales ubicamos aquellos trabajos que toman como línea rectora las representaciones fílmicas que abarcan áreas de la Argentina incorporadas tardíamente a la Nación, como por ejemplo la Patagonia o las zonas de frontera. Victor Arancibia ${ }^{32}$ analiza la cinta La guerra gaucha (1942), insertándola en la historiografía mitrista. Esta corriente dio luz a la versión tradicional de la historia enseñada en la escuela y fundó la mitología argentina que tenía como principal propósito nacionalizar a los pequeños alumnos. En su ponencia, Arancibia indaga sobre la importancia de la recreación ambiental cinematográfica cuyo objetivo es lograr la identificación del espectador con la representación del espacio narrado. Según el autor las imágenes fílmicas operan en el centro de la construcción de 
las identidades nacionales. De esta forma el cine actúa como un operador de la nacionalización y como un vehículo de las interpretaciones que una sociedad da sobre sí misma, desde un lugar privilegiado para hacer circular este tipo de simbolizaciones sociales.

Arancibia utiliza la noción de "espesor temporal" para dar cuenta de la memoria que poseen las representaciones, condensando sentidos que quedan sin perderse y posibilitando la actualización de los mismos en diferentes instancias socio-históricas.

Otra portavoz de este tipo de estudios es María de la Paz Escobar ${ }^{33}$, quién indaga sobre la incorporación tardía de la Patagonia a la Nación a partir de la famosa campaña militar llamada "Conquista del Desierto" en 1880.

En su trabajo, "Cine e historia: la Patagonia en imágenes" ${ }^{34}$, realiza un análisis comparativo de los films rodados entre 1936 y 1976, que tienen como espacio narrativo a aquel territorio argentino, intentando rastrear los aspectos que se reiteran. Según la autora la mayoría de las películas reproducen la visión de las clases dominantes donde el ejercicio civilizatorio se lleva a cabo por medio de las Fuerzas Armadas o de la burguesía. Entre otros elementos los films destacan la visión idílica del sur argentino: un paisaje desolado que se fue civilizando a la par de la ocupación y el desarrollo industrial. Se presenta una región sin nacionalizar y en constante amenaza por potencias extranjeras. A la Patagonia se la recrea como un desierto y una frontera; una lucha constante entre la civilización y la barbarie. Sin embargo las últimas producciones rompen con el discurso hegemónico y tradicional sobre esta región, al representar los sucesos conocidos como la "Patagonia rebelde", en donde el Ejército con la complicidad de la clase dominante local fusiló aproximadamente 1500 trabajadores rurales.

Un último caso que podríamos citar dentro de este conjunto de estudios regionales es la ponencia de Paula Inés Laguarda. ${ }^{35}$ Allí describe cómo se instala en la provincia de La Pampa el discurso de la modernidad y el progreso. Por medio del análisis de fotografías y luego de películas, documentales y de ficción, demuestra cómo fue concebido aquel territorio y de qué forma esa percepción reconfiguró la identidad nacional y local.

Más allá del enfoque espacial y regional, la construcción identitaria argentina es un tópico abordado desde la cinematografía doméstica y plausible de ser analizado en clave histórica. A través de un examen pormenorizado del film La guerra gaucha (1942) Didier y Levinson ${ }^{36}$ demuestran que esta película permite comprender la conformación de la identidad nacional y cultural del país, pues allí se exhiben las narraciones que la conformaron. En su trabajo ambos autores, teniendo en cuenta los clásicos debates sobre cine-historia, el contexto de producción y las intenciones de los realizadores, evidencian de qué manera esta obra representa los lugares comunes y personajes del imaginario 
popular que influyeron y a la vez edificaron interpretaciones históricas del nacionalismo argentino.

En el siguiente eje agrupamos aquellos estudios referidos a memoria y dictadura; es decir al análisis de las representaciones fílmicas que funcionan como herramientas de rescate de un pasado oscurecido por brutales fenómenos como lo fue la última dictadura cívico-militar en Argentina (1976-1983).

Stella Maris Poggian ${ }^{37}$ examina algunas películas realizadas durante transiciones democráticas, tanto la española como la argentina. Observa en el cine un vehículo artístico de la memoria, a la vez que da cuenta del posible uso pedagógico del mismo. La autora legitima las producciones fílmicas como materiales históricos dignos de ser preservados. Teniendo en consideración al proceso de reconstrucción de la memoria, rescata en el arte audiovisual una de las formas más potentes de canalizar el dolor de una sociedad cuyas heridas quedan aún abiertas.

Radetich y Jakubowicz ${ }^{38}$ también realizaron trabajos que pueden ubicarse dentro de este grupo. Ellos indagan los diversos componentes de la memoria de la última dictadura argentina mediante el análisis de películas ficcionales y documentales realizadas entre 1983 y 2003 . Dentro de este período distinguen tres etapas diferentes que evidencian la influencia del contexto de producción en el abordaje de distintos hechos históricos que moldean la reconstrucción fílmica de relatos sobre el terrorismo del Estado. De esta manera, exponiendo rupturas y continuidades temporales, los autores demuestran de qué forma en cada momento se priorizan ciertos elementos y visiones sobre el pasado para silenciar o dejar atrás otras cuestiones que atañen a la temática.

Ana Belén Zapata, como otros investigadores analizados previamente, entiende al cine como agente de la historia, como fuente del momento de elaboración y una forma distinta de narrar el pasado. Al trabajar con producciones fílmicas de realizadores como Raymundo Gleyzer dentro de la corriente del cine militante, percibe en el audiovisual un elemento o arma de contra-información para las bases. ${ }^{39}$

En la misma línea que Zapata, María de la Paz Escobar pone en juego la relación entre la coyuntura sociopolítica dentro de la cual son rodados los films con el momento histórico al que estos hacen referencia. Presenta a las películas, tal como lo hace Marc Ferro, como agentes de la historia o participantes directas en el devenir de los pueblos. El cine es concebido como un constructor de memorias y vehículo de resistencia. ${ }^{40}$

Por último Marta Casale ${ }^{41}$ analiza una serie de documentales históricos que presenta como claros ejemplos del cine político elaborado por una nueva generación de realizadores, en donde se destacan las producciones de agrupaciones como HIJOS (hijos de desaparecidos). En ellos se buscan las formas de deconstrucción de un discurso que ha sido oficializado y se detalla 
cómo estas representaciones cinematográficas intentan operar sobre la realidad convirtiendo al espectador en testigo de dicho proceso.

Un aspecto importante a tener en cuenta resulta ser la profundidad con que penetran los films en la estructura de sentimientos de las personas, es decir las emociones que logran despertar las películas dentro de cada uno de nosotros, dado que los films detentan el poder de trasladarnos al corazón mismo de los acontecimientos. Otro punto a considerar es que las imágenes cinéticas poseen la particularidad de permanecer más tiempo en la conciencia de un pueblo. Desde un primer momento los revolucionarios rusos se percataron de esa característica, razón por la cual no escatimaron dinero ni recursos para la producción cinematográfica con el simple y único objetivo de construir y propagar ideología. A partir de aquel entonces ningún gobierno contemporáneo estuvo exento de la utilización de los films con motivo de construcción de consenso y expansión de la ideología dominante.

Así, nuestro cuarto eje agrupa un conjunto de escritos que estudian la relación entre el Estado y el cine, haciendo hincapié en el rol de este último en la difusión de propaganda. Pablo Fontana ${ }^{42}$, profesor de la Cátedra de Historia de Rusia de la Universidad de Buenos Aires, desarrolló en la misma un ciclo de cinematografía rusa llamado "Sovietkino - Una retrospectiva histórica del cine ruso - soviético". Sus trabajos tienen como objeto de análisis la filmografía de Europa Oriental, principalmente la soviética y la de la República Democrática Alemana. ${ }^{43}$

Siguiendo el análisis de diversas producciones audiovisuales (largometrajes, noticieros, documentales, etc.) Fontana identifica ciertas problemáticas relacionadas con su tarea académica; como por ejemplo la legitimación del orden socialista en la República Democrática Alemana y la colectivización en la Unión Soviética. Apoyado en una amplia bibliografía que aborda diferentes temáticas (que van desde análisis institucionales y estéticos del cine hasta aquellas que desarrollan sus implicancias ideológicas) el autor llega a interesantes conclusiones acerca del medio audiovisual en cuestión. De acuerdo con su percepción éste se constituye como una potente herramienta de legitimación de un orden determinado y como un instrumento privilegiado de propaganda de las clases dirigentes. Así los films se establecen como vehículos ideológicos que van mutando con el tiempo según las necesidades coyunturales del momento histórico en los cuales fueron concebidos.

Por su parte, a través de una periodización de la República de Weimar, Mabel Mendieta expone cómo las producciones cinematográficas de la época expresan y se encuentran influenciadas por el contexto político y cultural característico de cada etapa de esta experiencia republicana. Siguiendo los planteos de Kracauer, la autora entiende a las películas como fuentes históricas 
capaces de captar las tendencias psicológicas del momento y el sentimiento de ciertos sectores sociales con respecto al Estado alemán en cuestión. ${ }^{44}$

Ceferino Bavasso ${ }^{45}$ se aproxima a la temática a través de la detallada exposición sobre las vinculaciones entre el cine y la política estatal nacional entre 1925 y 1938, focalizándose en la creación del Instituto Cinematográfico Argentino. Carina Bonnano y Silvia Zuppa ${ }^{46}$ abordan esta problemática por medio del análisis estético y del contexto de producción de dos documentales rodados en el I Festival Internacional de Cine de Mar del Plata (1954), financiados por el segundo gobierno de Perón. Las autoras evidencian la tendencia propagandística de las películas (enfatizando ciertos hechos y silenciando otros acontecimientos coyunturales) y revelan el uso político del medio audiovisual para educar a las masas e imponer creencias e ideas comunes del movimiento peronista.

Al indagar sobre la relación entre el cine y el estado peronista no podemos dejar de mencionar el libro Clara $\operatorname{Kriger}^{47}$ que se ha convertido en una obra de referencia para los investigadores de la temática. En el mismo analiza las películas de ficción del período, el contexto de producción y su vinculación con las políticas estatales del primer gobierno de Perón, proporcionando una relectura novedosa de esta etapa.

Gabriel Moya también estudia la cinematografía peronista pero estructurándola en dos grandes conjuntos. El primero se refiere a los filmes rodados mientras el peronismo estaba en el poder, en donde resalta el papel activo del Estado como agente de producción simbólica y difusión de propaganda. El segundo grupo toma como punto de partida a este movimiento popular ya proscripto y con su líder exiliado, donde las cintas lejos de gozar del beneplácito oficial son censuradas y circulan clandestinamente. El factor en común que une a ambos tipos de relato es la generación de mitos peronistas en coyunturas sociopolíticas totalmente diferentes. ${ }^{48}$

Un último exponente de este grupo es Damián Santos, quién investiga la cinematografía comunista y anarquista y su acción de propaganda en Argentina. El autor destaca que las películas fueron realizadas para intervenir en una disputa ideológica, lo cual explica las diferencias entre las distintas producciones al interior de la vanguardia obrera. Santos rescata el proceso de transmisión y recepción de los films, puesto que incorpora al análisis el espacio de proyección. La imagen entonces se potencia con el discurso político. ${ }^{49}$ 


\section{ORGANIZACIONES QUE FOMENTAN DESARROLLO DE ESTUDIOS SOBRE CINE E HISTORIA}

Finalmente, en esta sección del artículo creemos pertinente hacer una mención especial de dos espacios que propician y alientan la investigación y la divulgación del tipo de trabajos que hasta aquí hemos tratado.

El Centro de Investigación y Nuevos Estudios sobre Cine (CIyNE) funciona desde 1997 dentro del Instituto de Historia del Arte Argentino y Latinoamericano (Facultad de Filosofía y Letras de la Universidad de Buenos Aires). Este colectivo conformado por doctores, doctorandos, maestrandos, becarios, graduados y alumnos avanzados de las carreras de Artes (Facultad de Filosofía y Letras) y Comunicación Social (Facultad de Ciencias Sociales), funda el centro con el objetivo de crear un ámbito propicio para el debate y la reflexión de un sin número de temas vinculados al campo cinematográfico argentino y latinoamericano.

Durante el transcurso de los años CIyNe fue consolidándose a través de la realización de una amplia cantidad de actividades académicas y de extensión cultural, entre las cuales es posible mencionar: el desarrollo proyectos de investigación acreditados por la Universidad de Buenos Aires, el Consejo Nacional de Investigaciones Científicas y Tecnológicas (CONICET) y la Agencia Nacional de Promoción Científica y Tecnológica; la organización de conferencias, seminarios y encuentros académicos y la promoción y exhibición tanto nacional como internacional de producciones cinematográficas locales y latinoamericanas en ciclos y jornadas especiales.

A su vez, este equipo ha fomentado la divulgación científica por medio de diversas publicaciones. Entre ellas se destacan los cinco números la revista especializada Xanad $u^{50}$ y una serie de $\operatorname{libros}^{51}$ que compendia los trabajos de sus integrantes.

El otro espacio lo constituye la Asociación Argentina de Estudios de Cine y Audiovisual (AsAECA), creada en el año 2008. Esta joven institución surge con el propósito de nuclear a los profesionales vinculados al área de investigación y análisis de producciones cinematográficas y audiovisuales cuyas problemáticas resultan comunes a una cantidad de profesionales procedentes de distintos campos disciplinares: teoría del cine, estudios culturales, historia, sociología, antropología, educación, ciencias de la comunicación, realizadores, entre otros. Todos ellos participan de la Asociación con sus diversos aportes, los cuales permiten el fortalecimiento y la difusión de este tipo de abordajes.

Así, este espacio funciona como punto de encuentro interdisciplinario que por medio de congresos, conferencias, simposios, presentaciones fílmicas y otros eventos, intenta la formalización del tipo de trabajos que nos atañen tanto a nivel nacional como internacional. De esta forma se logra incentivar 
el intercambio de información y conocimiento provenientes de los distintos sectores vinculados con el cine y el audiovisual. A su vez, AsAECA promueve la divulgación de los avances en el área por medio de concursos y publicaciones de índole científica, ya sea en formato de revista o de libro. ${ }^{52}$

\section{CONCLUSIONES}

Hasta aquí hemos realizado un relevamiento sobre lo que últimamente se ha investigado y publicado en ámbitos académicos argentinos sobre la relación entre el cine y la historia.

Teniendo en cuenta lo expuesto en el presente artículo creemos que resulta alentadora la cantidad de proyectos que se han llevado a cabo durante estos años. Numerosos avances, por su diversidad temática y por la pluralidad de miradas, potencian un campo de estudio en constante formación que desde la academia ha sido relegado durante muchos años. Los motivos de esta reticencia fueron múltiples y respondieron a lo que tradicionalmente se entendió por ciencia histórica y la tarea propia del historiador; tanto frente a la comunidad científica como a la sociedad a la que se divulgaba el conocimiento del pasado. Así, por mucho tiempo, una gran cantidad de historiadores profesionales, arraigados a concepciones teóricas y metodológicas tradicionales, han rechazado al cine como una fuente digna de análisis.

Es sabido que la primera aproximación al conocimiento del pasado que la gran mayoría de la gente experimenta se da a partir de films históricos. En este punto creemos conveniente remarcar el creciente alejamiento entre la historia académica y el público general que se ha dado durante el siglo $\mathrm{XX}$, fenómeno que a su vez convivió con el nacimiento y el desarrollo de los medios audiovisuales que supieron aprovechar aquel vacío existente.

Las películas, al ser productos culturales de arte, de lenguaje visual y de representación de la realidad, se encuentran en la mira de todo examen de la sociedad y por ende son plausibles de ser abarcadas desde la Historia. Como hemos expuesto a lo largo del artículo, diversos autores han destacado la utilidad del cine como fuente auxiliar de la disciplina, como medio pedagógico, como instrumento ideológico-propagandístico y como agente mismo del devenir histórico. Todas estas cualidades han sido consideradas siempre con la salvedad de intentar un análisis crítico y apropiado de los textos fílmicos. Pues, estos presentan un lenguaje propio (disímil y no equiparable a la escritura) y como tales poseen la competencia de construir y transmitir un discurso determinado. ${ }^{53}$

Asimismo, se debe tener en cuenta que si bien las imágenes cinematográficas (e incluso las fotográficas) muchas veces poseen la pretensión de retratar la realidad, son una representación y una reconstrucción de la 
misma. Sin embargo, esto no quiere decir que no sean medios útiles para lograr interpretaciones más complejas de hechos históricos. Las narraciones de ficción pueden ir más allá de su función referencial y cumplir el rol de acercar el mundo del pasado al receptor del presente (en este caso al espectador). ${ }^{54}$

Partimos de la idea de que ciertas películas no sólo reproducen una narración histórica, sino que también proporcionan una aproximación al hecho del que se refieren y lo hacen a través de un lenguaje particular. Si bien no es equiparable a la historiografía, esta interpretación no puede ser obviada por la Academia, ya que en muchos casos alcanza entidad y valor social e incluso compite con las versiones eruditas.

De ésta forma, Pierre Sorlin ${ }^{55}$ aclara que, como historiadores, la riqueza de nuestra labor no se basa en la corroboración o comparación de los textos fílmicos con los escritos (aunque este proceso sea necesario) o en el preguntarnos por su grado de veracidad. Más bien debemos indagar en los aspectos político-ideológicos de los mismos y comprender los medios y los motivos por los cuales estos se presentan en relación a la sociedad a la que apelan.

Apoyándonos en lo expuesto a lo largo de nuestro artículo, creemos que el cine como medio audiovisual masivo proporciona una utilidad innegable a nuestra disciplina y se constituye como un instrumento de expresión cultural que no podemos desdeñar en la interpretación de fenómenos que nos atañen. Sostenemos que el cine presenta una diversidad de usos e información que desde la Historia podemos rescatar para enriquecer perspectivas y aproximaciones a nuestro pasado.

Sin embargo, la prosperidad progresiva de este tipo de investigaciones en los últimos años no deja de evidenciar una cantidad de interrogantes sin resolver y cuestiones que aún necesitan una mayor profundización en su desarrollo.

Al llevar a cabo el presente estado de la cuestión notamos que en muchos casos al examinar las películas se requiere más elaboración de preceptos teórico-metodológicos con el objeto de consolidar el estudio de los films desde nuestra disciplina. A su vez, resulta pertinente que en los mismos abordajes se reconozcan los objetivos y conceptos que guían el análisis fílmico en función del propósito de cada investigación. Esta reflexión deriva de la lectura de ciertos trabajos donde falta una exposición más pormenorizada de la relación entre el cine y la historia, pues si queremos expandir y desarrollar el campo de estudio, creemos fundamental recavar aspectos que evidencien un vínculo que en ocasiones se entiende como implícito. En este sentido, también pensamos que es imprescindible indagar en la problemática abierta por Ferro-Rosenstone, incorporarla como punto de partida y articularla con nuevas perspectivas que expongan claramente la finalidad y utilidad de cada análisis. 
Asimismo, esperamos que surjan más producciones interdisciplinarias que articulen diferentes perspectivas y contenidos para fortalecer y consolidar los abordajes. De igual forma confiamos en un futuro y fluido intercambio de ideas tanto a nivel nacional e internacional, en particular si tenemos en cuenta los nuevos espacios que están emergiendo para que éste se lleve a cabo.

Finalmente deseamos que la elaboración de estudios y el examen de los mismos inviten a un debate más profundo sobre la importancia del cine para nuestras tareas, ya sea en nuestro rol de investigadores, como el de docentes. Consideramos que esta discusión nos llevará a replantear las formas de abordar el pasado en ambos ámbitos y también nos ayudará a reflexionar acerca de los preceptos y conceptos que la guían.

Decir que desde la gran pantalla se elabora un discurso histórico implica replantearse qué entendemos por historia. Si aceptamos que en cierto sentido ésta es un constructo en donde se ponen en juego las subjetividades del investigador, podremos entender al cine como una manera particular de hacer historia, siempre y cuando no caigamos en el error de considerar el relato del pasado como un invento. Claro que todo relato es subjetivo. Sin embargo, la especificidad de la narración histórica reside en la interpretación de datos concretos y verificables, referidos a hechos reales que la separan del discurso literario e incluso del periodístico.

Entonces preguntas como ¿Qué entendemos por Historia? ¿Cuál es su función? ¿Cómo y con qué herramientas se produce el conocimiento? ¿Qué papel cumplimos como historiadores? son interrogantes que deben orientar permanentemente nuestra tarea para que ésta contribuya con aportes significativos no sólo para la comunidad científica sino también para el público no especializado. Creemos que el acercamiento de la disciplina a este último a través de diferentes estrategias y medios de expresión -sin por ello renunciar ni a la producción escrita ni al compromiso con la calidad académica- es una cuenta pendiente que tenemos como profesionales y comunicadores sociales. Es un desafío difícil, tal vez en ocasiones incómodo, que requiere de mucho trabajo pero pensamos que sin duda rendirá sus frutos.

\section{NOTAS}

1 NIGRA, Fabio (coord.). Visiones gratas del pasado. Hollywood y la construcción de la Segunda Guerra Mundial. Buenos Aires: Imago Mundi, 2012. p. 4.

2 A fines de la década de 1970, los investigadores franceses Marc Ferro y Pierre Sorlin inauguran las discusiones con respecto al binomio cine-historia. Ambos reconocen la existencia de films que poseen un valor histórico y social ya que son útiles para estudiar el momento en el que fueron producidos. Según Ferro, una película es una foto de la sociedad al momento de filmarla, un documento que permite intuir aquella parte de la sociedad que se oculta a 
simple vista. Más adelante el historiador norteamericano Robert Rosenstone profundizará este razonamiento y basado en los postulados del posmodernismo sintetizados por Hyden White revolucionará el campo de estudio planteando que la historia puede ser contada a través del cine. Lejos de ser un reflejo de la sociedad o de alguna visión historiográfica, las películas construyen una visión del pasado y al hacerlo proporcionan un relato sujeto a las reglas y a los problemas que suscita cualquier discurso histórico.

3 Aquí distinguimos el cine ficción del documental. Entendemos por cine de ficción a aquellas producciones fílmicas que no apelan intencionalmente al mismo grado de veracidad que las documentales. Al mismo tiempo las expectativas de veracidad del relato que el espectador presenta ante los films ficcionales resultan más flexibles que las que posee con los documentales.

${ }^{4}$ En los últimos diez años han proliferado en Congresos y Jornadas de Historia mesas temáticas dedicadas a la relación cine-historia. La mayoría de las ponencias consultadas fueron presentadas en los siguientes Congresos: X Jornadas Interescuelas/Departamentos de Historia, Universidad Nacional de Rosario, Santa Fe, 2005; V Jornadas Nacionales de Historia Moderna y Contemporánea, Universidad Nacional de Mar del Plata, Mar del Plata, 2006; XI Jornadas Interescuelas/Departamentos de Historia, Universidad Nacional de Tucumán, San Miguel de Tucumán, 2007; XII Jornadas Interescuelas/Departamentos de Historia, Universidad Nacional del Comahue, San Carlos de Bariloche, 2009; I Jornadas de Historia Contemporánea, Facultad de Filosofía y Letras, Universidad Nacional de Buenos Aires, 2009; V Jornadas de Trabajo sobre Historia Reciente, Universidad Nacional de General Sarmiento, Provincia de Buenos Aires, 2010 y XIII Jornadas Interescuelas/Departamentos de Historia, Universidad Nacional de Catamarca, San Fernando del Valle de Catamarca, 2011.

5 DELla MORA, Leandro. Pecados de Guerra durante la guerra de Vietnam. Cuando el victimario se convierte en víctima a través de la pantalla. Huellas de Estados Unidos. Estudios, perspectivas y debates desde América Latina, Buenos Aires, año I, n. 1, mayo 2011, p. 83-99. Disponible en: www.huellasdeeua.com.ar. Acceso en: 29 jun. 2012. NIGRA, Fabio. El discurso histórico hecho cine. La mirada norteamericana. De Sur a Norte, perspectivas sudamericanas sobre los Estados Unidos, Buenos Aires, Fundación Centro de Estudios Americanos, vol. 8, n. 16, 2007. NIGRA, Fabio. Sobre la historia norteamericana versión Hollywood. Algunas hipótesis de trabajo. Siembra. Revista de Artes y Humanidades. Universidad de Chapingo, n. 7, mayo 2007.

6 En las V Jornadas de Historia Moderna y Contemporánea, Mar del Plata, 2006: NIGRA, Fabio. Mississippi en Llamas, o cómo los chicos buenos del FBI vienen siempre a salvar a los pobres negros. En las XI Jornadas Interescuelas/Departamentos de Historia, San Miguel de Tucumán, 2007: NIGRA, Fabio. La (re)construcción del pasado norteamericano: How the west was won. En las XII Jornadas Interescuelas/Departamentos de Historia, San Carlos de Bariloche, 2009: BEVILACQUA, Gilda. Pandillas de Nueva York: Un acercamiento a la relación compleja entre el Cine y la Historia; CARBONE, Valeria. La guerra personal de Charlie Wilson (o la otra historia de la intervención norteamericana en la Guerra AfganoSoviética); DADAMO, Forencia. The green berets: La creación del discurso político a través de la pantalla; DELLA MORA, Leandro. Malcolm X de Spike Lee, una crítica al 'Sistema social americano'; FIAMENGO, Augusto. La Guerra Fría sube al cuadrilátero: Rocky Balboa vs. El 'imperio del mal'; FORTE, Anabella. Sindicalismo y movimiento obrero en el cine norteamericano; PICCINELLI, Mariana. Entre la profecía y la conquista de la libertad: la ideología del Destino Manifiesto llevada al cine. En las V Jornadas de Trabajo sobre Historia Reciente, Provincia de Buenos Aires, 2010: DADAMO, Florencia. La representación cinematográfica del pasado norteamericano y la utilización del western como elemento 
simbólico de consenso frente a la guerra de Vietnam; DELLA MORA, Leandro. La guerra de Vietnam. Cuando el victimario se convierte en víctima a través de la pantalla; PICCINELLI, Mariana. Ideas para una Nación: la doctrina del Destino Manifiesto en la pantalla grande. En las XIII Jornadas Interescuelas/Departamentos de Historia, San Fernando del Valle de Catamarca, 2011: BEVILACQUA, Gilda. Las representaciones fílmicas del pasado desde una mirada reciente y distópica: Bastardos sin gloria y la Segunda Guerra Mundial a través del cine; CARBONE, Valeria. La Guerra Cinematográfica: la Segunda Guerra Mundial y la construcción gubernamental del patriotismo norteamericano; DADAMO, Florencia. Operación Valquiria y las representaciones hollywoodenses del buen alemán; DELLA MORA, Leandro. La batalla de las Ardenas reconstruida por Hollywood, una apología de la guerra perpetua; FERNANDEZ MICKEL, Nicolás. Tensiones sociales en el frente de batalla. Los conflictos raciales en la cinematografía bélica sobre la Segunda Guerra Mundial; FIAMENGO, Augusto; MARTINI, Darío. Regreso a Bataán. La construcción hollywoodense del otro en el camino a la victoria; LACQUANITI, Leandro. Modelando la identidad norteamericana a través del cine. El relato bélico de la Segunda Guerra Mundial y la elaboración de un discurso hegemónico en las películas de Hollywood; NIGRA, Fabio. Historiografía y versiones cinematográficas. Una aproximación al cine histórico de Estados Unidos; PALLA, Jennifer. El cine enlistado. La industria cinematográfica al servicio de la guerra y la figura del obrero-soldado; PARDO, Emmanuel. Guerra en dos frentes. La definición de amigos y enemigos en la producción cinematográfica de los estudios Disney durante la Segunda Guerra Mundial; PICCINELLI, Mariana. Hollywood va a la guerra; TREJO, Darío. Patton ¿Herramienta del sistema para volver a 'aquellos años felices' ante el inconformismo o mero interés comercial ante la inestabilidad de los valores norteamericanos en decadencia?

7 NIGRA, Fabio (coord.). Hollywood, Ideología y consenso en la historia de Estados Unidos. Buenos Aires: Maipue, 2010. NIGRA, Fabio (coord.). Visiones gratas del pasado. Hollywood y la construcción de la Segunda Guerra Mundial. Buenos Aires: Imago Mundi, 2012. NIGRA, Fabio. Hollywood y la historia de Estados Unidos. La fórmula estadounidense para contar su pasado. Buenos Aires: Imago Mundi, 2012.

${ }^{8}$ Los UBACyT son proyectos de investigación acreditados y financiados por la Universidad de Buenos Aires que tienen como fin realizar un aporte sustancial al conocimiento académico del tema abordado y contribuir a la formación de investigadores. Los UBACyT dirigidos por el Dr. Fabio Nigra son "Hollywood como historiador. La fórmula norteamericana para generar consenso a través del cine" (UBACyT 448, 2008-2010), y "Visiones gratas del pasado: La Segunda Guerra Mundial a través del cine de Hollywood”' (UBACyT 20020090200338, 20102012).

9 Seminarios de Grado: "Cuando Hollywood hace Historia: La mirada del Cine sobre la Historia de los Estados Unidos en los siglos XVIII y XIX" (2005); "Hollywood como Historiador, o la fórmula norteamericana para construir un pasado de consenso desde el cine (1941-1990)" (2006); "Transmitiendo ideología con el Cine: Los grandes estudios y la visión del pasado en los Estados Unidos" (2008); "'In God We Trust': Las maneras de un pasado ideológico en las películas históricas de Estados Unidos de América”(2010). Seminario de Doctorado: "La historia de Estados Unidos y Hollywood: una forma de contar el pasado" (2011).

${ }^{10}$ NIGRA, Fabio. Sobre la historia norteamericana versión Hollywood. Algunas hipótesis de trabajo, op. cit.

${ }^{11}$ Ambos docentes de la carrera de Historia de la Universidad de Buenos Aires. Dictaron juntos el Seminario e Grado "La historia argentina a través del cine (1930-2005)" en la Facultad de 
Filosofía y Letras (UBA). Radetich por su parte actúa como formadora docente dentro de la cátedra de Didáctica Especial de la Historia, fue codirectora del UBACyT "Historia, cine y enseñanza" (UBACyT F811, 2006-2011) y dictó junto a Viviana Román, el seminario "Cine e Historia. El cine como representación social. La utilización de fuentes audiovisuales en la investigación y en la enseñanza de la historia" en la Facultad de Filosofía y Letras (UBA).

${ }^{12}$ JAKUBOWICZ, Eduardo; RADETICH, Laura. La historia argentina a través del cine. Las 'visiones del pasado' (1933-2003). Buenos Aires: La Crujía, 2006.

${ }^{13}$ JACUBOWICZ, Eduardo. Las visiones del 'pasado' o la 'historia' argentina a través del cine 1933-2003, algunos comentarios o reflexiones y RADETICH, Laura. El cine y la enseñanza de la historia. El panteón nacional a partir de los años 70. Ambos en: X Jornadas Interescuelas/ Departamentos de Historia, Rosario, 2005. RADETICH, Laura. Fernando Pino Solanas cineasta y cronista de la Argentina Reciente. En: XI Jornadas Interescuelas/Departamentos de Historia, San Miguel de Tucumán, 2007.

${ }^{14}$ Algunos de los máximos exponentes de esta escuela según los autores serían Marc Ferro, Robert Rosenstone, Pierre Sorlin, José Enrique Monterde, J.M. Caparrós Lera, Michele Lagny y Paul Ricoeur. Ver JAKUBOWICZ, Eduardo; RADETICH, Laura. La historia argentina a través del cine, op. cit., p. 13.

${ }^{15}$ Los períodos expansivos se desarrollan durante la década del cuarenta, entre los años 1968 y 1975 y desde 1983 en adelante; mientras que los regresivos tienen lugar durante la década del treinta, de 1950 a 1968 y 1976 a 1983.

${ }^{16}$ Marcela López es Licenciada en Comunicación de la Universidad Nacional de Córdoba y Alejandra Rodríguez es historiadora de la Universidad de Buenos Aires.

${ }^{17}$ LOPEZ, Marcela; RODRIGUEZ, Alejandra. De amor y de guerras: versiones fílmicas sobre la argentina de los caudillos. Filmhistoria, Barcelona, v. 14, n. 1, 2004. LOPEZ, Marcela; RODRIGUEZ, Alejandra. Versiones fílmicas de la argentina rosista. En: X Jornadas Interescuelas/Departamentos de Historia, Rosario, 2005. LOPEZ, Marcela; RODRIGUEZ, Alejandra. Malones de películas. Las estrategias de representación de los pueblos originarios en el cine argentino. Apuntes para pensar la relación entre cultura e imperialismo. En: XI Jornadas Interescuelas/Departamentos de Historia, San Miguel de Tucumán, 2007. LOPEZ, Marcela; RODRÍGUEZ, Alejandra. Una de indios y soldados en la frontera sur. Identidad y subalternidad en un western argentino: Guerreros y Cautivas. Filmhistoria, Barcelona, v. 18, n. 1, 2007.

${ }^{18}$ LOPEZ, Marcela; RODRÍGUEZ, Alejandra. "El testimonio de las imágenes. La Argentina del siglo XX a través del cine y la fotografía", charla dictada en CEPA(Escuela de Capacitación Docente), 2011. LOPEZ Marcela; RODRÍGUEZ, Alejandra. "Cine e historia: del origen del hombre a la Europa feudal en imágenes" y LOPEZ, Marcela; RODRÍGUEZ, Alejandra. "Cine e historia: de la independencia a la Argentina moderna en imágenes", ambos cursos dictados en el Centro Cultural Rojas, Universidad de Buenos Aires, 2011.

${ }^{19}$ LOPEZ, Marcela; RODRÍGUEZ, Alejandra. Los miedos en la sociedad. Buenos Aires: Ministerio de Educación, Ciencia y Tecnología, 2007.

${ }^{20}$ LOPEZ, Marcela; RODRIGUEZ, Alejandra. Un país de película. La historia argentina que el cine nos contó. Buenos Aires: Editorial del Nuevo Extremo, 2009.

${ }^{21}$ MARZORATI, Zulema; TAL, Tzvi. Introducción al Dossier Memorias, Identidades y Cine. Perspectivas contemporáneas sobre la imaginación del pasado. Imagofagia, Buenos Aires, 
Asociación Argentina de Estudios de Cine y Audiovisual, n. 4, 2011.

${ }^{22}$ Entre ellos podemos destacar: TAL, Tzvi. Del cine guerrilla a lo "grotético". La representación cinematográfica del latinoamericanismo en dos films de Fernando Solanas: La hora de los hornos y El viaje. Revista Estudios Interdisciplinarios de América Latina y el Caribe, vol.9, n. 1, enero-junio 1998. TAL, Tzvi. Dialéctica de Memoria y Olvido en Kamchatka. En: X Jornadas Interescuelas/Departamentos de Historia, Rosario, 2005.

${ }^{23}$ Seminarios de grado: "Cine e historia: la década del '30" (2005) y "Guerra Fría y Maccartysmo, entre la historia y el cine" (2006). Ambos dictados en la Facultad de Ciencias Sociales, Universidad de Buenos Aires.

${ }^{24}$ MARZORATI, Zulema. Representaciones cinematográficas de la Guerra Fría y el Maccarthysmo. En X Jornadas Interescuelas/Departamentos de Historia, Rosario, 2005. MARZORATI, Zulema; STELLA, Ma. Elena. La Segunda Guerra Mundial: Memorias de la Resistencia. En: V Jornadas Nacionales de Historia Moderna y Contemporánea, Mar del Plata, 2006.

${ }^{25}$ MATHEU, Cristina. El despoblamiento rural bonaerense reflejado en el film "Nueva Plata: ¡Acusa!” de M. Zipilivan. En: X Jornadas Interescuelas/Departamentos de Historia, Rosario, 2005.

${ }^{26}$ BATAGLIESE, Rodolfo. Las consecuencias del desempleo para los sectores medios en la Francia actual: sus representaciones en El empleo del tiempo (Cantet, 2001) y La Corporación (Costa-Gavras, 2005). En: XI Jornadas Interescuelas/Departamentos de Historia, San Miguel de Tucumán, 2007.

${ }^{27}$ Irene Marrone es Magister en Ciencias Sociales y actúa como profesora adjunta de la materia Historia Social Argentina de la Carrera de Sociología de la Facultad de Ciencias Sociales, UBA. Dicta cursos de posgrado en la Facultad de Ciencias Económicas y es investigadora independiente del Instituto de Investigaciones Gino Germani, ambas instituciones pertenecientes a la Universidad de Buenos Aires.

${ }^{28}$ En la bibliografía encontrada se destacan las publicaciones de libros y revistas: MARRONE, Irene. Imágenes del mundo histórico. Identidades y representaciones en el noticiero y el documental en el cine mudo argentino. Buenos Aires: Editorial Biblos, 2003. MARRONE, Irene; MOYANO WALTER, Mercedes. Persiguiendo imágenes: el noticiario argentino, la memoria y la historia (1930-1960). Buenos Aires: Editores del Puerto, 2006. MARRONE, Irene; MOYANO WALTER, Mercedes. Disrupción social y boom documental cinematográfico. Argentina en los años sesenta y noventa. Buenos Aires: Editorial Biblos, 2011. FARIÑA, Mabel; MARRONE, Irene. Más allá de héroes y villanos. Derechos Humanos, dictadura y memoria en el cine. Revista electrónica Afuera, año IV, n. 7, noviembre 2009. Disponible en: http://www.revistaafuera.com/NumAnteriores/pagina.php?seccion=Articulos\&page=03. Articulos.Marrone.Farina.htm\&idautor=67. Acceso en: 29 jun. 2012. FARIÑA, Mabel; MARRONE, Irene. Mesianismo y revolución. Tensiones en la representación cinematográfica del Plan de Erradicación de villas de emergencia de Onganía. Giroscopio, Mendoza, n. 1, 2009. LUCHETTI, Ma. Florencia. De la pacificación al Cordobazo. El noticiario cinematográfico argentino en la década del 60: discursividad social e identidad. Giroscopio, Mendoza, n. 1, 2009. También encontramos las presentaciones en Congresos y Jornadas: FARIÑA, Mabel; MARRONE, Irene. Más allá de héroes y villanos. Derechos Humanos, dictadura y memoria en el cine". En: XI Jornadas Interescuelas/Departamentos de Historia, San Miguel de Tucumán, 2007. MARRONE, Irene. "Las masas y el acto político en el cine informativo". En: Seminario Internacional: "Representaciones Audiovisuales de las Masas", Biblioteca Nacional, Buenos 
Aires, 2010. MARRONE, Irene. Panelista en el Primer Encuentro Nacional de Investigadores sobre Cine y Audiovisual en la Argentina, Universidad de Rosario, Santa Fe, 2011.

29 “Atrapando la realidad. Disrupción social y boom documental cinematográfico en los años sesenta y noventa en Argentina" (UBACyT S444, 2008-2010) y "Lo político y el documental cinematográfico en Argentina. Hacia una historia integral del documental cinematográfico en Argentina. 1897-2009” (UBACyT 01/1133 GF 2010-2012).

${ }^{30}$ RUSSO, Sebastián. Memoria, Identidad y Dictadura. Representaciones de lo privado y lo público en la película M. de Prividera. En: XI Jornadas Interescuelas/Departamentos de Historia, San Miguel de Tucumán, 2007.

${ }^{31}$ Un ejemplo lo constituye la Universidad del Comahue, que promueve la formación de grupos de trabajo financiados por el CONICET y la Agencia Nacional de Promoción Científica y Tecnológica.

${ }^{32}$ Víctor Arancibia es Magíster en estudios históricos y literarios de frontera y se desempeña como profesor de Introducción a las Teorías de la Comunicación Social y Teorías de la Percepción, en la carrera de Ciencias de la Comunicación de la Universidad Nacional de Salta y de Semiótica en la Licenciatura en Artes de la Universidad Católica de Salta. Ver ARANCIBIA, Víctor. El espesor temporal de las imágenes cinematográficas. A propósito de La guerra gaucha: representaciones sociales y condiciones de producción; en XI Jornadas Interescuelas/ Departamentos de Historia, San Miguel de Tucumán, 2007.

${ }^{33}$ María de la Paz Escobar es Licenciada en historia de la Universidad Nacional de la Patagonia San Juan Bosco.

${ }^{34}$ ESCOBAR, María de la Paz. Cine e historia: la Patagonia en imágenes (1936-1976). En: XI Jornadas Interescuelas/Departamentos de Historia, San Miguel de Tucumán, 2007.

${ }^{35}$ LAGUARDA, Paula Inés. Modernidad, cultura y cine en el territorio nacional de La Pampa. En: XI Jornadas Interescuelas/Departamentos de Historia, San Miguel de Tucumán, 2007. La autora es becaria del CONICET y pertenece a la Universidad Nacional de La Pampa.

${ }^{36}$ DIDER, Paula; LEVINSON, Andrés. La guerra gaucha como fuente histórica. De Lugones a Artistas Argentinos Asociados, un punto de partido. En: X Jornadas Interescuelas/ Departamentos de Historia, Rosario, 2005.

${ }^{37}$ POGGIAN, Stella Maris. Tiempo y espacio en la imagen documental y ficcional: la presencia de una ausencia. En: X Jornadas Interescuelas/Departamentos de Historia, Rosario, 2005. POGGIAN, Stella Maris. Cine y Memoria. La evocación del exilio argentino y la guerra civil española desde la perspectiva de Adolfo Aristarain y Carlos Saura. En: XII Jornadas Interescuelas/Departamentos de Historia, 2009. Stella Maris Poggian se doctoró en Comunicación Audiovisual en la Universidad Autónoma de Barcelona. Ejerce la docencia y la investigación en la Universidad Nacional del Comahue.

${ }^{38}$ JACUBOWICZ, Eduardo; RADETICH, Laura. Represión y desaparecidos, las representaciones a través del cine 1983-2005. En: V Jornadas Nacionales de Historia Moderna y Contemporánea, Mar del Plata, 2006.

${ }^{39}$ ZAPATA, Ana Belén. Miradas desaparecidas de la Historia: la figura de la traición sindical en el cine de Raymundo Gleyzer. En: XI Jornadas Interescuelas/Departamentos de Historia, San Miguel de Tucumán, 2007. Ana Belén Zapata es Licenciada en Historia por la Universidad Nacional del Sur. 
${ }^{40}$ ESCOBAR, María de la Paz. La masacre de Trelew: un análisis comparativo de sus representaciones fílmicas. En: XI Jornadas Interescuelas/Departamentos de Historia, San Miguel de Tucumán, 2007.

${ }^{41}$ CASALE, Marta Noemí Rosa. Representaciones de la dictadura en democracia. Represión y pérdida de identidad en el cine de la postdictadura. En: V Jornadas de de Trabajo sobre Historia Reciente, Provincia de Buenos Aires, 2010. Miembro del grupo C.I.yN.E., Casale trabaja en el proyecto "Historia del cine político y social en Argentina: formas, estilos y registros".

${ }^{42}$ Licenciado en Historia; docente de la Cátedra Historia de Rusia de la carrera de historia de la Facultad de Filosofía y Letras de la Universidad de Buenos Aires. Su tesis de licenciatura versó sobre "La representación cinematográfica del proceso de colectivización soviético". Su proyecto actual de tesis doctoral se titula "La representación del genocidio nacional-socialista en el cine de la URSS y la RDA", bajo la dirección de Ezequiel Adamovsky.

${ }^{43}$ FONTANA, Pablo. El proceso de colectivización en la URSS a través del cine soviético. En: V Jornadas Nacionales de Historia Moderna y Contemporánea, Mar del Plata, 2006. FONTANA, Pablo. La legitimación de la ocupación soviética de la RDA en el cine alemán oriental de posguerra. En: XI Jornadas Interescuelas/Departamentos de Historia, San Miguel de Tucumán, 2007. FONTANA, Pablo. Buscando los límites de la representación cinematográfica de Octubre en su décimo aniversario. En: ADAMOVSKY, Ezequiel; BAÑA, Martín; FONTANA, Pablo. Octubre rojo: la Revolución Rusa noventa años después. Buenos Aires: Libros del Rojas, 2009.

${ }^{44}$ MENDIETA, Mabel. Historia y Cine, Un Camino de Ida y Vuelta. El cine como fuente y el cine como otra forma de hacer historia. En: XI Jornadas Interescuelas/Departamentos de Historia, San Miguel de Tucumán, 2007.

${ }^{45}$ BAVASSO, Ceferino Cristian. El Cine Argentino entre 1925-1938 y sus relaciones con la política. En: X Jornadas Interescuelas/Departamentos de Historia, Rosario, 2005.

${ }^{46}$ BONNANO, Carina; ZUPPA, Silvia. El 1er Festival Internacional de Cine de Mar del Plata. Cine y propaganda política. En: X Jornadas Interescuelas/Departamentos de Historia, Rosario, 2005.

${ }^{47}$ KRIGER, Clara. Cine y peronismo. El Estado en escena. Buenos Aires: Siglo XXI Editores, 2009.

${ }^{48}$ MOYA, Gabriel. Del cine de propaganda al cine de militancia. La transmutación del peronismo en la pantalla, entre la Nueva Argentina y la Patria Socialista. En: X Jornadas Interescuelas/Departamentos de Historia, Rosario, 2005.

${ }^{49}$ SANTOS, Damián. Debate, cine, propaganda: la producción cinematográfica comunista y anarquista durante la guerra civil española y su acción de propaganda en Argentina. En: XII Jornadas Interescuelas/Departamentos de Historia, San Carlos de Bariloche, 2009.

${ }^{50}$ XANADU. Buenos Aires: Centro de Investigación y Nuevos Estudios sobre Cine, 19992003.

${ }^{51}$ LUSNICH, Ana Laura (Ed.). Civilización y Barbarie en el cine argentino y latinoamericano. Buenos Aires, Editorial Biblos, 2005. LUSNICH, Ana Laura. El drama social folclórico. El universo rural en el cine argentino. Buenos Aires: Editorial Biblos, 2007. LUSNICH, Ana Laura; PIEDRAS, Pablo (Eds.). Una historia del cine politico y social en Argentina. Formas, estilos y registros (1896-1969). Buenos Aires: Editorial Nueva Librería, 2009. PARDO, Soledad (Ed.). Un recorrido por cuatro films políticos argentinos en el marco de las "24 horas de Cine Nacional”. Buenos Aires: Centro de Investigación y Nuevos Estudios sobre Cine, 2010. 
LUSNICH, Ana Laura; PIEDRAS, Pablo (Eds.). Una historia del cine político y social en Argentina (1969-2009). Buenos Aires: Nueva Librería, 2011.

52 IMAGOFAGIA Revista digital. Buenos Aires: AsAECA, 2010-2011. Disponible en http:// www.asaeca.org/imagofagia/. Acceso en: 29 jun. 2012. ROMANO, Silvia; AGUILAR, Gonzalo (Coords.). ¿Qué he hecho yo para merecer esto? Guía del investigador de medios audiovisuales en Argentina. Buenos Aires: AsAECA, 2010. MOGUILLANSKY, Marina; MOLFETTA, Andrea; SANTAGADA, Miguel A. (Coords.). Teorías y Prácticas Audiovisuales. Actas del Primer Congreso de la Asociación Argentina de Estudios de Cine y Audiovisual. Buenos Aires: Teseo, 2010 y II CONGRESO DE LA ASOCIACIÓN ARGENTINA DE ESTUDIOS DE CINE Y AUDIOVISUAL, 2010, Buenos Aires. Actas del II Congreso... Buenos Aires: AsAECA, 2010. Disponible en: http://www.asaeca.org/actas.php?anio=2010. Acceso en: 29 jun. 2012.

${ }^{53}$ Ver ROSENSTONE, Robert. El cine histórico. En: El pasado en imágenes. El desafío del cine a nuestra idea de la historia. Barcelona: Ariel, 1997. ROSENSTONE, Robert. La historia en imágenes/la historia en palabras: reflexiones sobre la posibilidad real de llevar la historia a la pantalla. The American Historical Review., v. 93, n. 5, p. 1173-1185, dic. 1988. SANCHEZ, Alberto. El pasado a 24 imágenes por segundo: reflexiones sobre la utilidad del cine histórico. Cuadernos de Historia Moderna. Madrid, n. 12, 1991, p. 277-292.

${ }^{54}$ HENRIQUE VASQUEZ, Rodrigo. El problema de la verdad y la ficción en la novela y el cine históricos. A propósito de Lope de Aguirre. Manuscrits. Barcelona, n. 23, 2005, p. 94.

${ }^{55}$ SORLIN, Pierre. How to look at an 'Historical' Film. The film in History. Restaging the Past. USA: Barnes \& Noble Books, 1980.

Artigo recebido em junho de 2012. Aceito em agosto de 2012. 